\title{
Frontal vs. Posterior Cognitive Dysfunction: Does greater risk of dementia lead to differential gait in Parkinson's disease?
}

\author{
CAROLINA R. A. SILVEIRA ${ }^{1,2} \mid$ ERIC A. ROY1,2 | QUINCY J. ALMEIDA ${ }^{1}$ \\ ${ }_{1}$ Movement Disorders Research and Rehabilitation Centre, Wilfrid Laurier University, 75 University Avenue West, Waterloo, Ontario, N2L 3C5, CANADA. \\ 2University of Waterloo, Department of Kinesiology, 200 University Avenue West, Waterloo, Ontario, N2L 3G1, CANADA.
}

Correspondence to: Dr. Carolina R. A. Silveira, Parkwood Institute, 550 Wellington Road, London, ON, CANADA, N6C 0A7.

email: Carolina.Silveira@sjhc.london.on.ca

https://doi.org/10.20338/bjmb.v13i1.124

\author{
HIGHLIGHTS \\ -PD patients with different cognitive profiles \\ could not be distinguished based on gait. \\ -PD patients with frontal deficits performed \\ worse in the cognitive task when walking. \\ - Cognitive profile and PIGD subtype should be \\ considered in future research.

\begin{tabular}{|c|c|}
\hline \\
\hline \multicolumn{2}{|c|}{ ANOVA One-way analysis of variance } \\
\hline GDS & Geriatric Depression Scale \\
\hline PD & Parkinson's disease \\
\hline PIGD & postural instability and gait deficits \\
\hline MoCA & Montreal Cognitive Assessment \\
\hline $\mathrm{NCl}$ & no cognitive impairment \\
\hline PKMAS & $\begin{array}{l}\text { ProtoKinetics Movement Analysis } \\
\text { Software }\end{array}$ \\
\hline TMT & Trail Making Test \\
\hline UPDRS & $\begin{array}{l}\text { Unified Parkinson's disease } \\
\text { Rating Scale motor subsection }\end{array}$ \\
\hline
\end{tabular}

PUBLICATION DATE

Received 11Jan 2019

Accepted 24 Mar 2019

Published 01 May 2019
BACKGROUND: Gait impairment is suggested to predict the onset of dementia in Parkinson's disease (PD). Interestingly, studies have shown that PD patients with cognitive deficits mediated by posterior brain areas are at greater risk of developing dementia than those with frontal deficits. However, it remains unknown whether PD patients with posterior cognitive deficits show differences in gait when compared to those with frontal deficits.

AIM: This study aimed to compare gait of individuals with PD showing "posterior", "frontal", or no cognitive impairment (NCl).

METHOD: Based on a sample of 64 individuals with PD, median scores were calculated for three neuropsychological tests relying on "frontal" and three relying on "posterior" brain areas. Individuals assigned to the Frontal or Posterior groups showed at least 2 out of 3 scores lower than the median in frontal or posterior tests, respectively. Those with 0 or 1 score lower than the median were classified as $\mathrm{NCl}$. Participants walked under single and dual task conditions.

RESULTS: All groups walked slower, with greater variability, a wider base of support, and longer double support in the dual task condition.

CONCLUSION: PD patients with posterior cognitive deficits walk similarly to those with frontal deficits and those with normal cognition.

\section{INTRODUCTION}

Deficits in gait and cognition are commonly observed in individuals with Parkinson's disease (PD). Importantly, research has shown that PD patients with postural instability and gait deficits (PIGD) are at greater risk of developing dementia than those with tremor as the predominant motor symptom, ${ }^{1,2}$ and that gait characteristics at diagnosis predict decline in specific cognitive domains over time in PD. ${ }^{3}$ In this context, researchers have argued that changes in gait can precede and predict cognitive decline in PD and that the progression of gait and cognitive deficits could result from shared underlying mechanisms. ${ }^{4-7}$ Thus, gait has been proposed as a surrogate marker for dementia in PD. Although evidence exists that changes in gait predict the incidence of dementia in healthy older adults 8,9 and individuals with mild cognitive impairment, ${ }^{10}$ research investigating gait as a marker for dementia in PD is still in its early stages. If changes in gait are found to reveal individuals at greater risk of

\begin{tabular}{l|l|l|l|}
\hline $\begin{array}{l}\text { Silveira, Roy, } \\
\text { Almeida }\end{array}$ & 2019 & VOL.13 & N.1 \\
\end{tabular}


Brazilian Journal of Motor Behavior

dementia, then this information could contribute to early identification and intervention prior to dementia onset in PD.

Given that few longitudinal studies have examined the relationship between gait and cognitive decline in PD, a way of testing the potential of gait as a marker could be to compare gait characteristics of individuals with PD at a higher and lower risk of dementia and determine whether those at higher risk show distinct gait behavior. Previous research has demonstrated that two cognitive profiles at diagnosis differently predict the risk of dementia in PD. The first was characterized by deficits in cognitive domains that rely on frontal lobe functioning (i.e. executive functions) and respond to dopaminergic therapy, while the second was characterized by deficits in cognitive domains mediated by posterior brain areas (i.e. memory, language, and visuospatial functioning) that do not respond to dopamine. At 5 and 10-year follow up, it was found that a larger number of individuals with "posterior" deficits at diagnosis had developed dementia in comparison to those with "frontal" deficits. 11, 12 It was concluded that individuals with PD who show deficits in "posterior" cognitive domains at diagnosis of PD are at greater risk of dementia than those showing deficits in "frontal" cognitive domains. Thus, if gait is a marker for dementia in PD, then it could be hypothesized that differences in gait may exist between non-demented PD patients with "posterior" and "frontal" cognitive deficits.

To date, no study has directly compared gait of PD patients with predominantly "posterior" or "frontal" cognitive deficits. However, associations between gait and cognitive deficits in PD have been extensively reported. Interestingly, studies have consistently shown that slower gait speed and greater step-to-step variability were linked to frontal cognitive deficits. ${ }^{13,14}$ In contrast, the relationship between deficits in gait and cognitive domains mediated by posterior brain areas are inconsistent and more rarely reported. Although objective measures of gait stability, such as double support, ${ }^{15}$ as well as the severity of gait impairment and postural instability from the Unified Parkinson's disease Rating Scale, 16 have been associated with posterior cognitive deficits, these associations do not reveal whether differences in gait exist between groups at different risk for dementia.

This study aimed to compare gait of non-demented individuals with PD showing predominantly "posterior", "frontal", or no cognitive impairment (NCl). Given the associations between gait instability and posterior cognitive deficits, it was expected that individuals with predominant posterior deficits would walk with a wider base of support and longer double support than those with frontal deficits and $\mathrm{NCl}$. Since previous research has shown associations between step-to-step variability and frontal deficits, it was hypothesized that individuals with predominantly frontal deficits would walk with greater step-to-step variability than those with posterior deficits and $\mathrm{NCl}$. As gait speed could be associated with frontal and/or posterior deficits, it was expected that the frontal as well as posterior groups would walk slower than the $\mathrm{NCl}$ group. Finally, it was hypothesized that, due to its greater demands on cognitive processing, differences between groups would have greater magnitude when participants performed dual task gait compared to single task gait.

METHODS 


\section{Research Article}

This study was approved by Wilfrid Laurier University (WLU) and University of Waterloo (UW) research ethics boards (process identification numbers: 19582 and 3922) and informed consent was obtained prior to participation.

\section{Participants}

Sixty-four individuals with PD were recruited from the Movement Disorders Research and Rehabilitation Centre database at WLU (Waterloo, Canada). Inclusion criteria were men and women diagnosed with idiopathic PD by a Neurologist and able to walk 10 meters unassisted. Participants were excluded if one of the following criteria was met: history of neurological diseases other than PD, uncontrolled diabetes, uncontrolled hypertension, history of cardiovascular disease, chronic obstructive pulmonary disease, uncorrected visual impairments, and a diagnosis of dementia. Participants' demographic information (age, sex, and years of education), general cognitive function (Montreal Cognitive Assessment), depressive symptoms (Geriatric Depression Scale), and motor disease severity (Unified Parkinson's disease Rating Scale motor subscale) were collected at baseline.

\section{Group Assignment}

Based on performance of all 64 individuals with PD, median scores were calculated for each neuropsychological test relying predominantly on "frontal" or "posterior" brain functioning. Participants were assigned to Frontal $(n=14$; age $=68.50(7.83))$ or Posterior $(n=12$; age $=69.25(8.50))$ groups if they showed at least 2 of 3 scores lower than the median in frontal or posterior tests, respectively. Participants with 0 or only 1 test score lower than the median were classified as non-cognitively impaired ( $\mathrm{NCl} \mathrm{n=22;} \mathrm{age=67.59} \mathrm{(8.09)),} \mathrm{and}$ those with lower scores in both frontal and posterior tests were excluded $(n=16)$. Groups' demographic and clinical information are displayed in Table 1.

Table 1-Demographic and clinical information

\begin{tabular}{c|c|c|c|c|c|c}
\hline Group & Age (years) & Sex $(\mathrm{M} / \mathrm{F})$ & $\begin{array}{c}\text { Education } \\
\text { (years) }\end{array}$ & MoCA & GDS & UPDRS-III \\
\hline Frontal $\mathrm{n}=14$ & $68.50(7.83)$ & $8 / 6$ & $14.00(3.80)$ & $25.78(1.88)$ & $5.35(3.73)$ & $24.25(7.19)$ \\
\hline Posterior $\mathrm{n}=12$ & $69.25(8.50)$ & $10 / 2$ & $16.58(3.57)$ & $25.00(3.69)^{c}$ & $6.66(5.82)$ & $23.00(7.04)$ \\
\hline $\mathrm{NCI} \mathrm{n}=22$ & $67.59(8.09)$ & $16 / 6$ & $15.45(3.01)$ & $27.63(2.19)$ & $6.36(4.50)$ & $25.09(9.90)$ \\
\hline
\end{tabular}

Legend: $\mathrm{NCl}$ - non-cognitively impaired; Education - number of years completed in school; MoCA - Montreal Cognitive Assessment; GDS - Geriatric Depression Scale; UPDRS-III - Unified Parkinson's disease Rating Scale motor subsection; : Posterior different from $\mathrm{NCl}$.

\section{Cognitive Assessment}

To assess cognitive domains relying on frontal brain functioning, three executive function tests were employed: Digit Span ${ }^{17}$, Stroop Test ${ }^{18}$, and Trail Making Test ${ }^{19}$ (TMT). Median values were calculated based on the total number of digit sequences correctly recalled in the forward and backward conditions of the Digit Span, interference scores of the Stroop test (number of items correctly named in the Color-Word condition minus items correctly named in the Color condition), and the difference between parts B and A of the TMT in seconds. Assessment of cognitive domains relying on posterior brain functioning was conducted using the Copy of the Intersected Pentagons from the Mini Mental State Examination $^{20}$ (visuospatial), Semantic Verbal Fluency (language) ${ }^{21}$, and the Short Form

\begin{tabular}{l|l|l|l|}
\hline $\begin{array}{l}\text { Silveira, Roy, } \\
\text { Almeida }\end{array}$ & 2019 & VOL.13 & N.1 \\
\hline
\end{tabular}


Brazilian Journal of Motor Behavior

California Verbal Learning Test 22 (memory). Median values were calculated based on the total score in the Copy of the Intersected Pentagons, total number of words generated in the Semantic Verbal Fluency (semantic category: animals), and number of correct words recalled (immediate recall) in the California Verbal Learning Test.

\section{Gait Assessment}

Participants walked on a 10-meter long Zeno® Walkway System (ProtoKinetics, Havertown, PA, USA) under single and dual task conditions ( 3 trials per condition). Three trials per condition were performed to examine the effects of task novelty ( $1^{\text {st }}$ trial) and adaptation (subsequent trials), while making the protocol feasible to participants with different severities of gait impairment. In the single task condition participants were instructed to walk at their normal pace, whereas in the dual task condition they were instructed to walk and count the number of times that two pre-assigned digits were spoken on an audio track. ${ }^{23}$ Participants started walking 1 meter prior to stepping onto the carpet and continued walking 1 meter after stepping off the carpet to account for gait acceleration and deceleration phases. In addition, the first and last steps were removed from the analysis to eliminate the effect of surface transition. Gait speed, step length and step time variability (coefficient of variation=(standard deviation/mean)x100), base of support (step width), and percentage of time spent in double support ((total double support time/stride time)x100) were calculated using the ProtoKinetics Movement Analysis Software (PKMAS) version 507c7c.

\section{Statistical Analysis}

One-way analysis of variance (ANOVA) or a non-parametric test (Kruskal Wallis) was used to compare demographic, clinical, and neuropsychological information between groups. Repeated Measures ANOVA tested differences in gait between groups in task conditions and experimental trials [Group x Condition x Trial]. Repeated Measures ANOVA was used to compare participant performance in the secondary task while sitting versus walking [Group x Condition]. Significant differences were examined using Tukey's HSD posthoc test or non-parametric pairwise comparisons (Mann-Whitney $U$ ) and alpha levels were kept at $\leq 0.05$.

\section{RESULTS}

\section{Demographic and clinical information}

Overall, groups had similar age, years of education, severity of depressive symptoms, and motor disease severity. However, group differences were found in the MoCA $\left(F(2,45)=4.71 ; p=0.013 ; \eta^{2}=0.17\right)$, where the Posterior group presented a worse general cognitive status than the $\mathrm{NCl}$ group $(p=0.017)$.

\section{Cognition}

Neuropsychological testing was used primarily to classify individuals into experimental groups based on median performance per test. However, performance in neuropsychological tests was also compared after group assignment in order to confirm whether distinct patterns of deficits emerged. Group differences were found for the Stroop

\begin{tabular}{l|l|l|l|}
\hline $\begin{array}{l}\text { Silveira, Roy, } \\
\text { Almeida }\end{array}$ & 2019 & VOL.13 & N.1 \\
\hline
\end{tabular}


Brazilian Journal of Motor Behavior

test $\left(F(2,45)=5.86 ; p=0.005 ; \eta^{2} p=0.20\right)$, TMT $(X 2(2)=14.21 ; p=0.001 ;$ mean rank score Frontal=35.29, Posterior=25.17, $\mathrm{NCl}=17.27)$, Digit Span $\left(\mathrm{F}(2,45)=13.75 ; p<0.0001 ; \eta^{2} p\right.$ $=0.37$ ), Copy of the Intersected Pentagons $(X 2(2)=18.90 ; p<0.001$; mean rank score Frontal=26.29, Posterior=12.92, $\quad \mathrm{NCl}=29.68)$, and Semantic Fluency $(\mathrm{F}(2,41)=7.09$; $\left.p=0.002 ; \eta^{2} p=0.25\right)$. Post-hoc analysis showed that the Frontal group performed worse than both Posterior and $\mathrm{NCl}$ groups in the Stroop (Posterior $\mathrm{p}=0.038 ; \mathrm{NCl} p=0.005$ ), TMT (Posterior $p=0.035 ; \mathrm{NCl} p<0.001$ ), and Digit Span (Posterior $p=0.001 ; \mathrm{NCl} p=0.0001$ ) tests, whereas no differences between Posterior and $\mathrm{NCl}$ groups were found in these tests. The Posterior group performed worse than both Frontal $(p=0.004)$ and $\mathrm{NCl}(p<0.001)$ groups in the Copy of Intersected Pentagons, and worse than the NCl group ( $p=0.001)$ in the Semantic Fluency test. Group performances in the neuropsychological tests are presented in Table 2.

Table 2-Group performance in neuropsychological tests

\begin{tabular}{c|c|c|c|c|c|c}
\hline Group & Stroop & TMT & Digit Span & Pentagons & Semantic Fluency & CVLT \\
\hline Frontal $\mathrm{n}=14$ & $-33(10.74)^{\mathrm{a}}$ & $93.85(65.78)^{\mathrm{a}}$ & $13.92(2.43)^{\mathrm{a}}$ & $9.78(0.42)$ & $20.30(3.19)$ & $6.78(1.57)$ \\
\hline Posterior $\mathrm{n}=12$ & $-24.08(8.07)$ & $50.91(37.79)$ & $18.66(3.67)$ & $8.83(1.11)^{\mathrm{b}}$ & $16.30(3.30)^{\mathrm{c}}$ & $5.83(1.85)$ \\
\hline $\mathrm{NCI} \mathrm{n}=22$ & $-22.95(8.05)$ & $31.77(20.88)$ & $19.40(3.26)$ & $9.86(0.63)$ & $22.66(5.36)$ & $7.18(1.43)$ \\
\hline
\end{tabular}

Legend: Stroop - difference between the number of items correctly named in the Color-Word and Color conditions (negative value denotes greater interference); TMT - difference between parts B and A of the Trail Making Test in seconds (larger value denotes worse performance); Digit Span - total number of digit sequences correctly recalled in the forward and backward conditions (larger value denotes better performance); Pentagons - total score on the Copy of Intersected Pentagons (larger value denotes better performance); Semantic Fluency - total number of words correctly generated (larger value denotes better performance); CVLT - number of correct words recalled (immediate recall) in the short form of the California Verbal Learning Test (larger value denotes better performance). ${ }^{a}$ Frontal different from Posterior and $\mathrm{NCl}$; ${ }^{b}$ Posterior different from Frontal and $\mathrm{NCl}$; ${ }^{c}$ Posterior different from $\mathrm{NCl}$.

\section{Gait}

A main effect of Condition was found in the analysis of all gait-related variables, showing that when performing the dual task all groups walked slower $(F(1,45)=72.45$; $\left.p<0.001 ; \eta^{2}=0.61\right)$, with greater step length $\left(F(1,45)=12.17 ; p=0.001 ; \eta^{2}=0.21\right)$ and step time $\left(F(1,45)=11.06 ; p=0.001 ; \eta^{2} p=0.19\right)$ variability, a wider base of support $(F(1$, $\left.45)=16.60 ; p<0.001 ; \eta^{2} p=0.26\right)$, and longer double support $\left(F(1,45)=56.08 ; p<0.001 ; \eta^{2} p\right.$ $=0.55)$ compared to single task walking. However, no group differences were identified in either single or dual task walking conditions. Figure 1 shows the average values between groups for each outcome measure.

\begin{tabular}{l|l|l|l|}
\hline $\begin{array}{l}\text { Silveira, Roy, } \\
\text { Almeida }\end{array}$ & 2019 & VOL.13 & N.1 \\
\end{tabular}



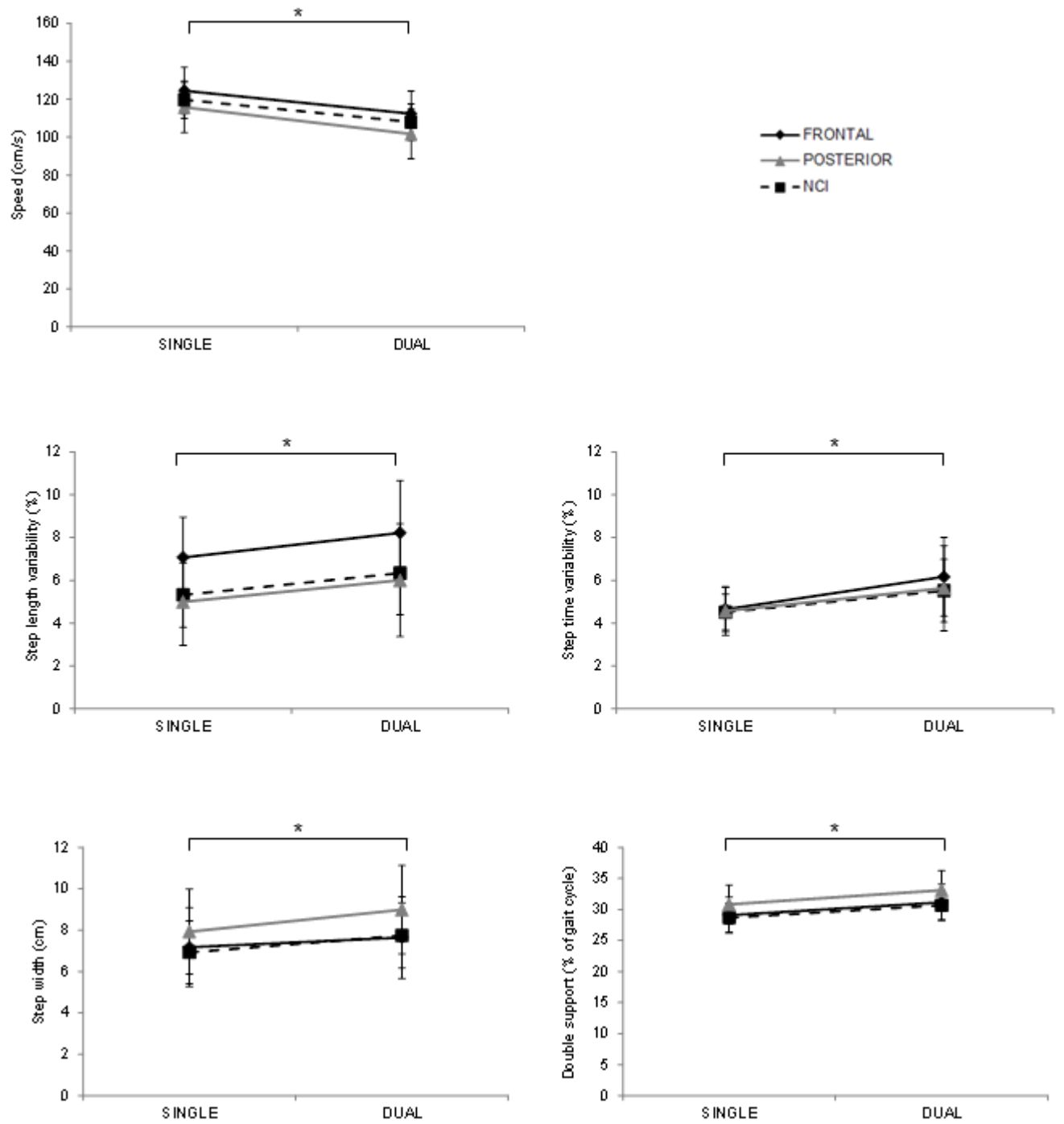

Figure 1.Groups showed similar behavior during single and dual task walking.

Performance in the secondary task was similar between groups while seated, confirming that all participants were able to perform this digit monitoring task. A group by condition interaction $\left(F(2,45)=5.43 ; p=0.007 ; \eta^{2} p=0.19\right)$ showed that only the Frontal group presented significantly more errors when walking compared to sitting $(p=0.029)$.

\section{DISCUSSION}

To our knowledge, this is the first study to directly compare gait behavior of nondemented PD patients with either predominantly frontal, posterior, or no cognitive impairment. Contrary to the study's hypotheses, results showed that all groups walked 
Brazilian Journal of Motor Behavior

similarly during single and dual task conditions. Despite previous investigations showing associations between gait and cognitive deficits in PD, 3, 13-15, 24 the gait of participants in the Frontal and Posterior groups did not differ from those in the $\mathrm{NCl}$ group. The lack of differences between groups is also in contrast with findings that the PIGD motor subtype is a predictor of cognitive decline in PD. 1, 2 In the current study, participants were categorized based on cognitive profile in order to identify individuals with deficits previously linked to an increased risk of dementia in PD. However, early research has shown that gait characteristics at diagnosis are better predictors of cognitive decline over time than cognitive characteristics. ${ }^{3}$ Therefore, it might be that categorization based on cognitive profile alone does not fully capture the relationship between gait, cognition, and risk of dementia in PD. It is also important to note that the relationship between gait and cognition in PD may depend on stratification based on predominant motor symptoms (tremor vs. PIGD), since associations between gait and cognitive decline in PD have been found in those with predominant PIGD but not predominant tremor symptoms ${ }^{1,2}$. Thus, in addition to cognitive profile, PIGD subtype should be taken into consideration when examining the relationship between, gait, cognition, and risk of dementia in PD.

With respect to performance in the secondary task, it was found that participants in the Frontal group had worse performance while walking compared to sitting. This result suggests that individuals with Frontal deficits experienced greater interference in cognitive processing or that these individuals prioritized gait in order to sustain performance during the dual task condition. Notably, the secondary task utilized in this study relied on working memory, a cognitive function largely processed in the frontal areas of the brain. ${ }^{25}$ Thus, the nature of the secondary task likely contributed to individuals in the Frontal group suffering greater interference than those in the Posterior and $\mathrm{NCl}$ groups. Future research should examine how secondary tasks tapping into different cognitive domains influence gait in PD patients with distinct cognitive profiles.

Findings from this research may have been influenced by its cross-sectional design, as it would be preferable to characterize gait and cognitive profiles at the time of diagnosis and follow individuals longitudinally in order to test the study hypotheses. In addition, sample size and assignment criteria may have attenuated differences between groups. Thus, it is suggested that future studies with larger samples use normative data for neuropsychological tests in order to identify and categorize individuals with impaired cognitive function.

\section{CONCLUSION}

The present study demonstrated that, in a cross-sectional design, PD patients with a cognitive profile linked to increased risk of dementia could not be distinguished based on gait.

\section{REFERENCES}


Brazilian Journal of Motor Behavior

\section{Research Article}

1. Burn DJ, Rowan EN, Allan LM, Molloy S, O'Brien JT, McKeith IG. Motor subtype and cognitive decline in Parkinson's disease, Parkinson's disease with dementia, and dementia with Lewy bodies. J Neurol Neurosurg Psychiatry. 2006; 77(5): 585-9.

2. Zhu K, van Hilten JJ, Marinus J. Predictors of dementia in Parkinson's disease; findings from a 5-year prospective study using the SCOPA-COG. Parkinsonism Relat Disord. 2014; 20(9): 980-5.

3. Morris R, Lord S, Lawson RA, et al. Gait Rather Than Cognition Predicts Decline in Specific Cognitive Domains in Early Parkinson's Disease. J Gerontol A Biol Sci Med Sci. 2017; 72(12): 1656-62.

4. Mollenhauer B, Rochester L, Chen-Plotkin A, Brooks D. What can biomarkers tell us about cognition in Parkinson's disease? Mov Disord. 2014; 29(5): 622-33.

5. Rochester L, Galna B, Lord S, et al. Decrease in Abeta42 predicts dopa-resistant gait progression in early Parkinson disease. Neurology. 2017; 88(16): 1501-11.

6. Rochester L, Yarnall AJ, Baker MR, et al. Cholinergic dysfunction contributes to gait disturbance in early Parkinson's disease. Brain. 2012; 135 (Pt 9): 2779-88.

7. Bohnen NI, Frey KA, Studenski S, et al. Gait speed in Parkinson disease correlates with cholinergic degeneration. Neurology. 2013; 81(18): 1611-6.

8. Verghese J, Wang C, Lipton RB, Holtzer R, Xue X. Quantitative gait dysfunction and risk of cognitive decline and dementia. J Neurol Neurosurg Psychiatry. 2007; 78(9): 929-35.

9. Montero-Odasso M, Speechley M, Muir-Hunter SW, et al. Motor and Cognitive Trajectories Before Dementia: Results from Gait and Brain Study. J Am Geriatr Soc. 2018; 66(9): 167683.

10. Montero-Odasso M, Sarquis-Adamson Y, Speechley M, et al. Association of Dual-Task Gait With Incident Dementia in Mild Cognitive Impairment: Results From the Gait and Brain Study. JAMA Neurol. 2017; 74(7): 857-65.

11. Williams-Gray CH, Evans JR, Goris A, et al. The distinct cognitive syndromes of Parkinson's disease: 5 year follow-up of the CamPalGN cohort. Brain. 2009; 132(Pt 11): 2958-69.

12. Williams-Gray CH, Mason SL, Evans JR, et al. The CamPalGN study of Parkinson's disease: 10-year outlook in an incident population-based cohort. J Neurol Neurosurg Psychiatry. 2013; 84(11): 1258-64.

13. Lord S, Rochester L, Hetherington V, Allcock LM, Burn D. Executive dysfunction and attention contribute to gait interference in 'off' state Parkinson's Disease. Gait Posture. 2010; 31(2): 169-74.

14. Yogev G, Giladi N, Peretz C, Springer S, Simon ES, Hausdorff JM. Dual tasking, gait rhythmicity, and Parkinson's disease: which aspects of gait are attention demanding? Eur J Neurosci. 2005; 22(5): 1248-56.

15. Amboni M, Barone P, luppariello L, et al. Gait patterns in Parkinsonian patients with or without mild cognitive impairment. Mov Disord. 2012; 27(12): 1536-43. 
Brazilian Journal of Motor Behavior

\section{Research Article}

16. Domellof ME, Elgh E, Forsgren $\mathrm{L}$. The relation between cognition and motor dysfunction in drug-naive newly diagnosed patients with Parkinson's disease. Mov Disord. 2011; 26(12): 2183-9.

17. Wechsler D. Wechsler Memory Scale-Revised manual. San Antonio, Texas: The Psychological Corporation. 1987.

18. Stroop JR. Studies of interference in serial verbal reactions. J Exp Psychol.1935; 18: 64362.

19. Tombaugh TN. Trail Making Test A and B: normative data stratified by age and education. Arch Clin Neuropsychol. 2004; 19(2): 203-14.

20. Folstein MF, Folstein SE, McHugh PR. "Mini-mental state". A practical method for grading the cognitive state of patients for the clinician. J PsychiatrRes. 1975; 12(3): 189-98.

21. Troyer AK, Moscovitch M, Winocur G, Leach L, Freedman M. Clustering and switching on verbal fluency tests in Alzheimer's and Parkinson's disease. J IntNeuropsychol Soc. 1998; $4(2): 137-43$.

22. Delis DC, Kramer LH, Kaplan E, Ober BA. California Verbal Learning Test (CVLT-II). Second Edition ed. San Antonio, Texas: Psychological Corporation. 2000.

23. Pieruccini-Faria F, Jones JA, Almeida QJ. Motor planning in Parkinson's disease patients experiencing freezing of gait: the influence of cognitive load when approaching obstacles. Brain Cogn. 2014; 87: 76-85.

24. Rochester L, Hetherington V, Jones D, et al. Attending to the task: interference effects of functional tasks on walking in Parkinson's disease and the roles of cognition, depression, fatigue, and balance. Arch Phys Med Rehabil. 2004; 85(10): 1578-85.

25. Curtis CE, D'Esposito M. Persistent activity in the prefrontal cortex during working memory. Trends Cogn Sci. 2003; 7(9): 415-23.

\section{ACKNOWLEDGEMENTS}

The authors would like to thank Patricia Freeman for her assistance with participants' recruitment, as well as Brittany Intzandt and Rebecca Chow for their contribution to data collection.

\begin{tabular}{l|l|l|l|l}
\hline $\begin{array}{l}\text { Silveira, Roy, } \\
\text { Almeida }\end{array}$ & 2019 & VOL.13 & N.1 &
\end{tabular}




\section{P)}

\section{Research Article}

Brazilian Journal of Motor Behavior

Citation:Silveira CRA, Roy EA, Almeida QJ. Frontal vs. Posterior Cognitive Dysfunction: Does greater risk of dementia lead to differential gait in Parkinson's disease? BJMB.2019: 13(1): 1-10.

Editor:Dr Fabio Augusto Barbieri - São Paulo State University (UNESP), Bauru, SP, Brazil; Dr José Angelo Barela São Paulo State University (UNESP), Rio Claro, SP, Brazil; Dr Natalia Madalena Rinaldi - Federal University of Espirito Santo (UFES), Vitória, ES, Brazil.

Copyright: @ 2019Silveira, Roy and Almeida and BJMB. This is an open-access article distributed under the terms of the Creative Commons Attribution-NonCommercial-NoDerivatives 4.0 International License which permits unrestricted use, distribution, and reproduction in any medium, provided the original author and source are credited.

Funding:This research was supported by the National Council for Scientific and Technological Development CNPq/ Brazil [grant number 200703/2010-2]; Canada Foundation for Innovation [grant number 20774]; and Natural Sciences and Engineering Research Council of Canada [grants numbers 613003 and 9642].

Competing interests: The authors have declared that no competing interests exist.

DOI: https://doi.org/10.20338/bjmb.v13i1.124 